\title{
Epithelial barrier formation by airway basal cells
}

\author{
J S Erjefält, F Sundler, C G A Persson
}

\begin{abstract}
Background - Epithelial shedding processes in airway inflammation and defence may produce damaged areas where basal cells are the main remaining epithelial cell type. The present study examines the capacity of basal cells to form an epithelial barrier structure after loss of columnar epithelial cells.

Methods - A technique was developed which allows selective removal of columnar epithelial cells from isolated airways. A drop of tissue adhesive glue was applied on the mucosal surface shortly after excision of guinea pig trachea and human bronchus. Gentle removal of the glue, together with attached columnar cells, left a single layer of cobbled, solitary basal cells. The tissue was kept in culture media. Morphological changes of the basal cells were monitored by immunohistochemistry and scanning and transmission electron microscopy at several time points.
\end{abstract}

Results - After 20 minutes the basal cells had undergone extensive flattening and established contact with each other. The basement membrane thus became covered by a poorly differentiated epithelium in both guinea pig and human airways. Abundant interdigitating cytoplasmic protrusions were observed at cell borders.

Conclusions - Basal cells promptly flatten out to cover the basement membrane at loss of neighbouring columnar cells. These data may explain why the epithelial barrier function may be uncompromised in desquamative airway diseases. Furthermore, they suggest the possibility that sacrificial release of columnar epithelial cells and prompt creation of a barrier structure constitute important roles of basal cells in airway defence against severe insults.

(Thorax 1997;52:213-217)

Clinical Pharmacology

C G A Persson

University Hospital, Lund, Sweden

Correspondence to: Dr J S Erjefält, Department of Physiology and

Neuroscience, Lund

University, Experimental

University, Experimental

Research Center, E-Blocket,
University Hospital, 22185

Lund, Sweden.

Received 11 December 1996 Accepted for publication

16 December 1996

Keywords: basal cells, epithelial shedding, epithelial repair, barrier restitution.

Loss of the columnar barrier cells of the respiratory mucosa would allow penetration of inhaled allergens and other environmental agents into vulnerable and strongly reacting airway tissue components. In asthma (and rhinitis) epithelial shedding may thus cause disease progression and airway hyperresponsiveness. However, mucosal permeability in allergic airway disease is a controversial issue and failures of physiological tests to corroborate an increased inward perviousness of the airway mucosa in asthma ${ }^{1}$ and rhinitis ${ }^{2}$ is a continuing enigma. ${ }^{3}$ The apparent inconsistency between epithelial damage and lack of barrier dysfunction may in part be explained by the high speed of airway epithelial restitution after denudation. ${ }^{45}$ If complete denudation occurs, bordering secretory and ciliated cells thus dedifferentiate into flattened cells that migrate quickly (about $2 \mu \mathrm{m} / \mathrm{min}$ ) to cover the naked basement membrane. ${ }^{56}$ We reasoned that, if only columnar epithelial cells are lost, the airways should be even more apt than at complete denudation to produce a new barrier structure. ${ }^{6}$

In a previous study Wang et $a l^{7}$ observed flattening of basal cells by day 4 after smoke exposure but did not report early changes in these cells. Other previous reports ${ }^{89}$ on "basal cell changes" after epithelial injury suffer from uncertainties concerning what degree of injury has been inflicted, at what point in time shedding has occurred and, in the end, what cells have actually been examined.

We have now developed a method for selective removal of epithelial columnar cells from well defined areas of airway whole mount preparations. In this model, where attempts are made to maintain an in vivo like milieu, we have examined structural changes occurring as early as 20 minutes in basal cells that have lost their cover of columnar cells. The experimental focus is on guinea pig trachea complemented by observations in human bronchus. These airways are equipped with similar pseudostratified epithelium.

\section{Methods}

Male guinea pigs (Dunkin-Hartley, $300 \mathrm{~g}$ ) were sacrificed by intraperitoneal injection of pentobarbitone sodium $(1 \mathrm{ml} / \mathrm{kg})$ and the tracheas were rapidly excised in toto and rinsed with $0.9 \% \mathrm{NaCl}$. Human bronchi were obtained from two patients who were undergoing lobectomy for lung cancer. Freshly excised lung normal appearance (about $5 \mathrm{~mm}$ in diameter) were dissected out, cut into segments $(\sim 1 \mathrm{~cm}$, $n=6 /$ patient), opened longitudinally, and stretched out on Sylgard-coated petri dishes using microneedles. lobes were placed in Kreb's buffer. Bronchi of 
LECTIN HISTOCHEMISTRY

In the guinea pig tracheal preparations used for immunohistochemistry and subsequent scanning electron microscopy the columnar epithelial cells were stained using lectin histochemistry. Tracheal segments were connected to a plastic catheter (outer diameter $1.8 \mathrm{~mm}$ ) and the mucosal surface was gently rinsed with fluorescein isothiocyanate (FITC)-labelled lectin $\mathrm{B}_{4}$ from Bandeira simplicifolia (Sigma, $\mathrm{St}$ Louis, USA) diluted to $10 \mu \mathrm{g} / \mathrm{ml}$ in PBS buffer for five minutes at room temperature (lectin $\mathrm{B}_{4}$ does not penetrate the intact epithelial barrier). Tracheal segments were then rinsed, cut along the ventral side, and stretched out on petri dishes. Lectin-stained epithelium displayed the same morphology and ciliary activity as nonstained control epithelium (data not shown).

REMOVAL OF COLUMNAR EPITHELIAL CELLS Guinea pig or human preparations were gently rinsed with PBS buffer and placed in air for one minute, allowing the remaining fluid to evaporate until the mucosal surface became matt. The evaporation of the thin meniscus of water was observed using a preparation microscope with side illumination from a fibreoptic light source. Drops of tissue adhesive glue (Histoacryl, B Braun, Melsungen, Germany) with a diameter of about $5 \mathrm{~mm}$ were applied to the mucosal surface and allowed to harden in air for 30 seconds before cell culture medium (Dulbecco's modified Eagle's medium supplemented with $10 \%$ fetal calf serum, 5\% plasma, streptomycin and benzyl penicillin, $0.1 \mathrm{~g} / \mathrm{l}$ ) was added to the tissue. After $30 \mathrm{sec}-$ onds the polymerised glue was gently removed with forceps and the specimens were rinsed with culture medium and incubated in the same medium in a carbon dioxide incubator (Biocenter 2001, Salvis, Germany) at $37^{\circ} \mathrm{C}$ until termination of the experiment.

TERMINATION OF THE EXPERIMENT AND TISSUE PROCESSING

The experiment involving guinea pig preparations was terminated at $0,20,40$, and 90 minutes after removal of columnar cells $(n=4$ at each time point). Each tracheal preparation was cut into two segments. One segment was processed for immunohistochemistry and subsequent scanning electron microscopy, the other for transmission electron microscopy (see below). The tracheal preparations used for combined immunohistochemistry and scanning electron microscopy were immersed in fixative ( $2 \%$ formaldehyde in PBS buffer) for five minutes, rinsed with buffer, dehydrated through graded ethanol solutions and then rehydrated, rinsed with buffer, and subjected to immunohistochemical analysis (see below). The specimens were then examined with a fluorescence microscope and columnar and basal epithelial cells were visualised by epiillumination using excitation light with $495 \mathrm{~nm}$ (visualisation of FITC, lectin stained columnar cells) and $552 \mathrm{~nm}$ (visualisation of TRITC, cytokeratin $13,15,16$-stained basal cells) wavelength. The distribution of columnar and basal cells was recorded on double exposed photographs. The tracheal preparations were then subjected to scanning electron microscopy as described below. The degree of columnar epithelial cell loss was examined immediately after the removal of columnar epithelial cells. To examine possible effects of tracheal preparation, stretching, and incubation on the mucosal structure, separate preparations (in which the gluing was omitted but otherwise treated as above) were analysed at 0,40 , and 90 minutes $(n=9)$ and compared with "naive tracheas" which were collected and immersed in fixative immediately after sacrifice $(n=3)$. These controls were cut into segments and subjected to immunohistochemical visualisation of basal cells (on cryo sections) and transmission electron microscopy. Specimens for cryosectioning were frozen in freezing medium (Tissue-tek, Miles Inc, USA) immediately after excision. The experiments involving human bronchus were terminated after 0,20 , and 40 minutes of incubation. The preparations were then placed directly in fixative and subjected to scanning and transmission electron microscopy (see below).

\section{IMMUNOHISTOCHEMISTRY}

Antibodies ${ }^{10}$ recognising cytokeratin 13,15 , and 16 were used for immunohistochemical visualisation of epithelial basal cells. Airway cryostat sections of whole mount preparations were exposed to the primary antibody (monoclonal anticytokeratin, clone no. K8.12, Sigma, dilution 1:40 in PBS supplemented with $0.25 \%$ triton $\mathrm{X}$ ) overnight at $4^{\circ} \mathrm{C}$. After thorough rinsing in $\mathrm{PBS}+0.25 \%$ triton $\mathrm{X}-100$ the samples were incubated with secondary antibodies for one hour at room temperature. After rinsing in PBS $+0.25 \%$ triton X-100 the specimens were mounted in PBS:glycerine (1:1) and then examined with a fluorescence microscope. As secondary antibody a tetramethylrhodamine isocyanate (TRITC)-labelled goat anti-mouse IgG antibody (Jackson, West Grove, Pennsylvania, USA, dilution 1:80) was used. No staining was found in control sections incubated with only secondary antibodies or normal goat serum.

SCANNING AND TRANSMISSION ELECTRON MICROSCOPY

Tracheal whole mount preparations were immediately placed in fixative (PBS buffer containing $1 \%$ glutaraldehyde and 3\% formaldehyde) overnight and the specimens were processed for routine scanning electron microscopical analysis. ${ }^{11}$ With the aid of previously recorded distribution of columnar and basal cells on fluorescence micrographs it was possible to examine specifically areas with basal cell epithelium where no lectin-stained columnar cells were present. For transmission electron microscopy tracheal segments were immersed in a fixative (same as for scanning electron microscopy), fixed overnight, and processed 
as described previously. ${ }^{11}$ The samples were examined using a Jeol 200 CX or Philips CM10 transmission electron microscope.

\section{Results}

SELECTIVE REMOVAL OF COLUMNAR EPITHELIAL CELLS

Examination of lectin-stained cryo sections from guinea pig control tracheas revealed that the lectin staining was restricted to the apical lining of columnar epithelial cells (fig 1a). Immunohistochemical analysis of control epithelium showed an intense immunoreactivity for cytokeratin 13, 15, and 16 restricted to basal cells (fig 1b). Examination of whole mount preparations of control tracheas (subjected to both columnar and basal cell staining) showed a lectin-stained epithelial surface (fig 1c). After de-epithelialisation, lectin-stained columnar cells were almost completely absent in the manipulated area and a single layer of cytokeratin 13,15,16-immunoreactive basal cells remained

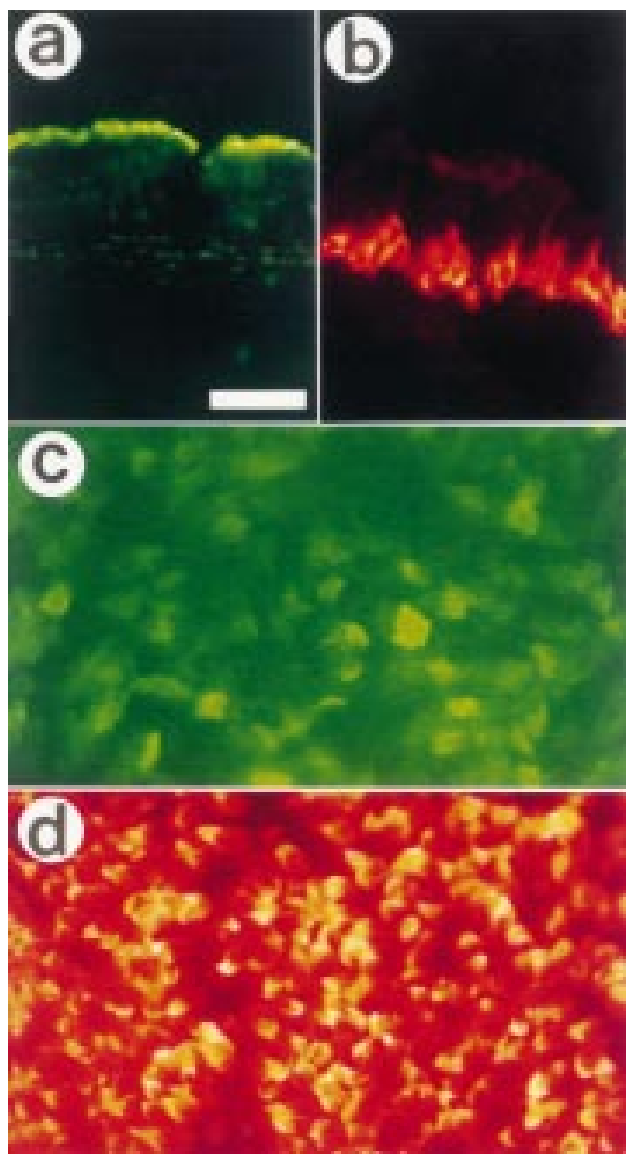

Figure 1 Fluorescence micrographs demonstrating the distribution of FITC-labelled lectin (green in a,c) and TRITC-labelled (red in b,d) cytokeratin $(13,15,16)$ immunoreactive cells in the epithelium. Cryo sections from control tracheas reveal that only the apical part of the columnar epithelial cells are lectin-labelled (a), whereas the immunoreactivity for cytokeratin 13,15, and 16 is restricted to basal cells (b). Double stained whole mount preparations revealed the pattern of lectin-stained columnar epithelial cells (observed from above) in nonglued areas (c, FITC image only). Glued areas display a glued areas (c, FIT layer of immunoreactive basal cells $(d$, combined
single FITC and TRITC) with no lectin-stained cells. Scale bars $100 \mu \mathrm{m}$. over the basement membrane (fig 1d). Scanning electron microscopy showed sharp borders between the remaining intact epithelium and the area subjected to columnar cell removal. Only a few scattered columnar epithelial cells could be detected in the glued area. These remaining cells were found in clusters, thus creating small "islets" of easy recognisable intact epithelium. Examination of the removed glue confirmed that columnar but not basal cells were attached to the polymerised glue.

STRUCTURAL CHANGES IN BASAL CELLS AFTER LOSS OF COLUMNAR EPITHELIAL CELLS

Only glued areas displaying an absence of lectin-stained columnar cells were used to examine changes in basal cells. Immediately after the de-epithelialisation procedure a single layer of cells with a cobbled morphology was present (fig 2a). After 20 minutes of incubation an extensive flattening of most remaining basal cells was observed (fig 2b); overlapping cytoplasmic protrusions were present at the borders between the cells (fig 2c). Scattered cells with a similar morphology to the original solitary basal cells were also seen in between the flattened cells (fig 2b). Transmission electron microscopy confirmed the presence of interdigitating cytoplasmic protrusions at cell borders. In areas with relatively few remaining basal cells the basement membrane was covered by thin cytoplasmic protrusions (fig $2 d)$. No apparent further structural changes of the basal cells could be observed at 40 and 90 minutes. Bright field and transmission electron microscopy revealed that basal cells in nonglued control tracheas displayed normal in situlike morphology - for example, no flattening had occurred - after 40 and 90 minutes of incubation.

A single layer of rounded basal cells remained in the glued area immediately after removal of the columnar epithelial cells from the human bronchial preparations (fig $2 \mathrm{e}$ and $\mathrm{f}$ ). At 20 and 40 minutes these remaining cells displayed a flattened morphology, similar to that observed in the guinea pigs, and had established apicolateral cell-cell contacts through overlapping cytoplasmic protrusions (fig $2 \mathrm{~g}$ ).

\section{Discussion}

By using a gluing technique it was possible to remove the columnar epithelial cells selectively from the tracheal explants. This manoeuvre left behind a single sheet of cobbled basal cells that had flattened out by 20 minutes and made frequent cell border contacts. Thus, the basement membrane became covered by an undifferentiated epithelium quite distinct from the loosely connected or separated basal cells present immediately after columnar cell deepithelialisation. These data suggest that the basal cells may be well equipped to take over a barrier structure promptly when columnar epithelial cells are shed. Such a property of airway basal cells would be important in health and disease. 

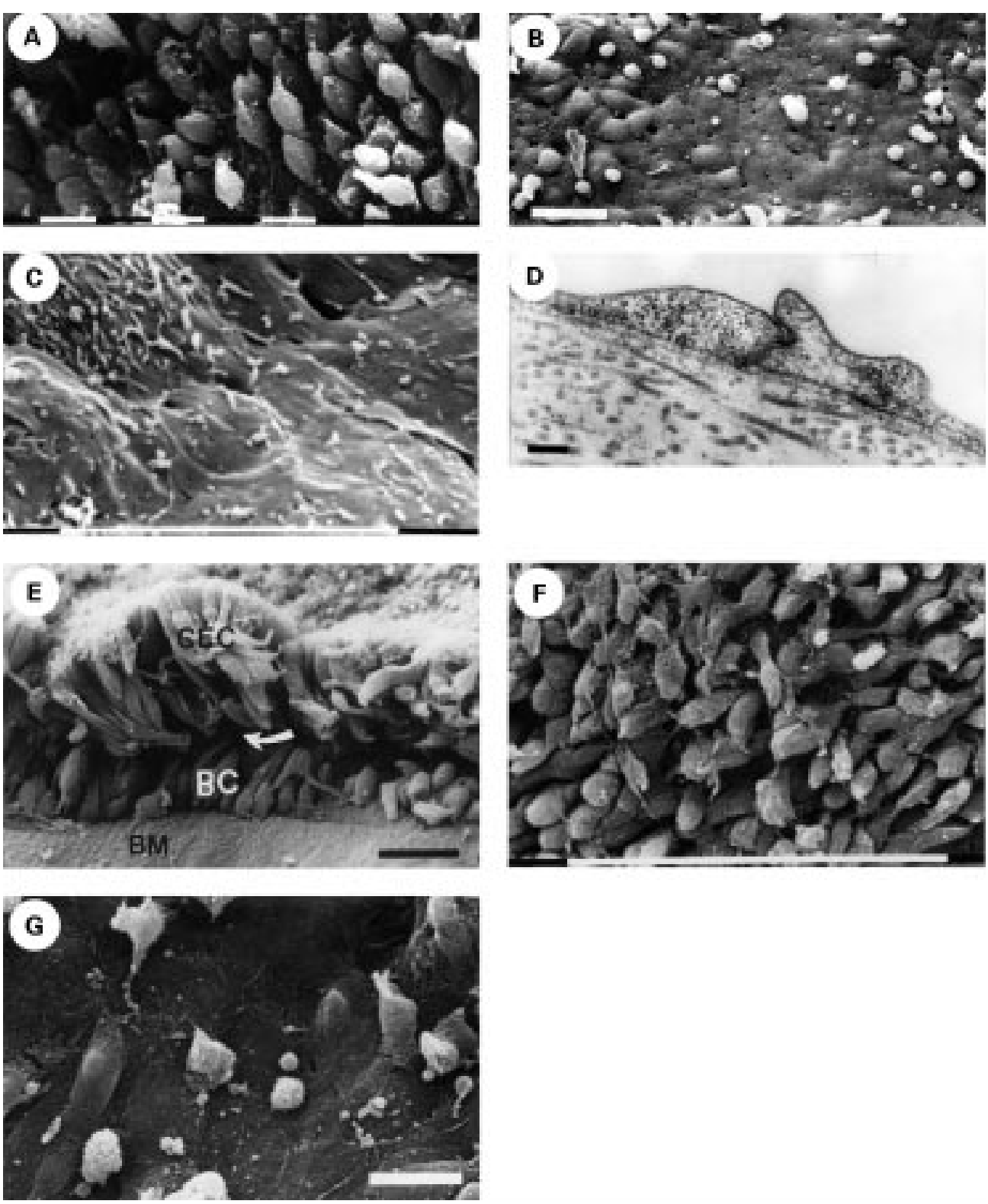

Figure 2 Electron micrographs of guinea pig trachea $(A-D)$ and human bronchi $(E-G)$. Immediately after removal of the glue a layer of cobble-like basal cells remains on the basement membrane (A). After 20 minutes numerous cells with flattened morphology can be observed (B). The non-flattened round cells scattered in (B) have not been identified but may be basal cells injured by the gluing procedure. Higher magnification reveals the presence of overlapping cytoplasmic membranes at the borders between flattened cells $(C)$. In areas with few remaining basal cells an extreme flattening may occur to cover the basement membrane. Figure 2D depicts overlapping cytoplasmic protrusions at the cell border between these flattened cells. Figure $2 E$ illustrates the pseudostratified morphology of the human bronchial epithelium. This picture is obtained by carrying out mechanical denudation, as previously described, ${ }^{5}$ in a fixed bronchial specimen; the arrow indicates the "site of cleavage" between the columnar (CEC) and basal epithelial (BC) cells. A few seconds after removal of the columnar cells the mucosal surface is covered by a single layer of cobble-like basal cells $(F)$. After 20 minutes the remaining cells have become flattened to form a continuous apical cell layer $(G)$. Scale bars: $A, C=10 \mu m$, $B=40 \mu \mathrm{m}, D=400 \mathrm{~nm}, E=20 \mu \mathrm{m}, F=100 \mu \mathrm{m}, G=15 \mu \mathrm{m}$.

Airway basal cells had long been considered the main stem cell from which secretory and ciliated cells derive ${ }^{12}$ when, during the 1980 s, this particular role was transferred almost entirely to the secretory cell. ${ }^{13}$ However, recent data suggest that both the ciliated and secretory cells participate equally in generating the poorly differentiated flat epithelium that provides the first cellular cover of denuded basement membranes in vivo. ${ }^{5}$ In the late 1980 s Evans and coworkers ${ }^{14}$ proposed that the major role of the basal cell is to anchor columnar epithelial cells to the basement membrane. Thus, the actual attachment of columnar epithelial cells to the underlying tissue is through basal cells that have hemidesmosomal contact with the basement membrane. ${ }^{14}$ The present findings support the notion that shedding of columnar cells can generally occur in human and guinea pig large airways without loss of basal cells.

The extensive flattening of basal cells and the interdigitating cytoplasmic protrusions at cell borders observed in this study would contribute a provisional epithelial barrier structure. 
In view of the possibility that columnar epithelial cells may have to be sacrificed in airway infection and inflammation and in defence, the readiness of the basal cells to flatten out becomes an important property of these cells. It is even conceivable that the actual release of neighbouring columnar cells could constitute a significant function of basal cells. Indeed, with a speedily established basal cell barrier patchy shedding of columnar cells may be regarded a proper respiratory defence mechanism at severe challenges of the mucosa of both nasal ${ }^{15}$ and tracheobronchial airways. The rapid change in shape of basal cells, which provides flattened cell contacts with potentially reduced stretches of epithelial junctions available for absorption, may also explain in part the apparent paradox of well maintained or even improved mucosal barrier function in desquamative airway diseases. ${ }^{3}$

We conclude that basal cells promptly create a barrier structure at shedding of columnar epithelial cells and suggest that the release of columnar epithelial cells should be considered an important airway defence mechanism.

This work was supported by the Swedish Medical Research Council projects 8308 and 4499, The Medical Faculty, University of Lund, and Astra Draco, Lund.

1 Elwood RK, Kennedy S, Belzberg A, Hogg JC, Paré PD. Respiratory mucosal permeability in asthma. Am Rev Respir Dis 1983;128:523-7.
2 Greiff L, Wollmer P, Svensson C, Andersson M, Persson CGA. Effect of seasonal allergic rhinitis on airway mucosal absorption of chromium-51-labelled EDTA. Thorax 1993 48:648-50.

3 Persson CGA, Andersson M, Greiff L, Svenson C, Erjefält JS, Sundler F, et al. Airway permeability. Clin Exp Allergy 1995;23:807-14.

4 Erjefält JS, Korsgren M, Nilsson MC, Sundler F, Persson CGA. Prompt epithelial damage and restitution processe in allergen challenged guinea-pig trachea in vivo. Clin Exp Allergy 1997 (in press)

5 Erjefält JS, Erjefält I, Sundler F, Persson CGA. In vivo restitution of the airway epithelium. Cell Tissue Res 1995; 281:305-16.

6 Persson CGA, Erjefält JS. Airway epithelial restitution after shedding and denudation. In: Crystal RG, West JB, Weibe ER, Barnes PJ, eds. The Lung: The Scientific Foundations of Health and Disease, 2nd edn. Philadelphia: LippincottRaven, 1996: 2611-27.

7 Wang CZ, Evans MJ, Cox RA, Burke AS, Zhu O, Herdnon $\mathrm{DN}$, et al. Morphologic changes in basal cells during repai of tracheal epithelium. Am f Pathol 1992;141:753-9.

8 Hilding AC. Regeneration of respiratory epithelium after minimal surface trauma. Ann Otol Rhinol Laryngol 1965 74:903-14

9 Gordon RE, Lane BP. Regeneration of rat tracheal epithelium after mechanical injury. Am Rev Respir Dis 1976; 113:799-807.

10 Wetzels RH. Basal cell specific and hyperproliferation-related keratins in human breast cancer. Am f Pathol 1991; 138:751-63.

11 Erjefält JS, Sundler F, Persson CGA. Eosinophils, neutrophils and venular gaps in the airway mucosa at epithelial removal-restitution. Am $\mathcal{F}$ Respir Crit Care Med 1996;153: 1666-74.

12 Jeffery PK. Structural, immunologic, and neural elements of normal human airway wall. In: Busse WW, Holgate ST, eds. Asthma and rhinitis. London: Blackwell, 1995: 80-108.

13 McDowell EM, Newkirk C, Coleman B. Development of hamster tracheal epithelium. I. A quantitative morphologic study in the fetus. Anat Rec 1985;213:429-47.

14 Evans MJ, Cox RA, Shami SG, Bilson B, Plopper CG. The role of basal cells in attachment of columnar cells to the basal lamina of the trachea. Am $\mathcal{F}$ Respir Cell Mol Biol 1989;1:463-9.

15 Erjefält JS, Greiff L, Sundler F, Persson CGA. Basal cells promtly flatten out at detachment of the columnar epipromtly flatten out at detachment of the columnar epi-
thelium in human and guinea-pig airways. Eur Respir $\mathcal{f}$ 1995;8:207. 